\title{
BMJ Open Cost-effectiveness of investing in sidewalks as a means of increasing physical activity: a RESIDE modelling study
}

\author{
J Lennert Veerman, ${ }^{1}$ Belen Zapata-Diomedi, ${ }^{1}$ Lucy Gunn, ${ }^{2,3}$ Gavin R McCormack, ${ }^{4}$ \\ Linda J Cobiac, ${ }^{1,5}$ Ana Maria Mantilla Herrera, ${ }^{1}$ Billie Giles-Corti, ${ }^{2}$ Alan Shiell ${ }^{3,6}$
}

To cite: Veerman JL, ZapataDiomedi B, Gunn L, et al. Cost-effectiveness of investing in sidewalks as a means of increasing physical activity: a RESIDE modelling study. BMJ Open 2016;6: e011617. doi:10.1136/ bmjopen-2016-011617

- Prepublication history and additional material is available. To view please visit the journal (http://dx.doi.org/ 10.1136/bmjopen-2016011617).

Received 23 February 2016 Revised 22 August 2016 Accepted 1 September 2016

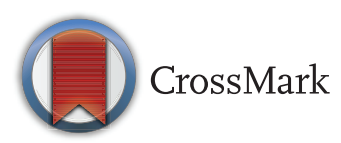

For numbered affiliations see end of article.

Correspondence to Dr Belen Zapata-Diomedi; b.zapatadiomedi@uq.edu.au

\section{ABSTRACT}

Background: Studies consistently find that supportive neighbourhood built environments increase physical activity by encouraging walking and cycling. However, evidence on the cost-effectiveness of investing in built environment interventions as a means of promoting physical activity is lacking. In this study, we assess the cost-effectiveness of increasing sidewalk availability as one means of encouraging walking.

Methods: Using data from the RESIDE study in Perth, Australia, we modelled the cost impact and change in health-adjusted life years (HALYS) of installing additional sidewalks in established neighbourhoods. Estimates of the relationship between sidewalk availability and walking were taken from a previous study. Multistate life table models were used to estimate HALYs associated with changes in walking frequency and duration. Sensitivity analyses were used to explore the impact of variations in population density, discount rates, sidewalk costs and the inclusion of unrelated healthcare costs in added life years.

Results: Installing and maintaining an additional $10 \mathrm{~km}$ of sidewalk in an average neighbourhood with 19000 adult residents was estimated to cost $A \$ 4.2$ million over 30 years and gain $24 \mathrm{HALYs}$ over the lifetime of an average neighbourhood adult resident population. The incremental cost-effectiveness ratio was $A \$ 176$ 000/HALY. However, sensitivity results indicated that increasing population densities improves cost-effectiveness.

Conclusions: In low-density cities such as in Australia, installing sidewalks in established neighbourhoods as a single intervention is unlikely to cost-effectively improve health. Sidewalks must be considered alongside other complementary elements of walkability, such as density, land use mix and street connectivity. Population density is particularly important because at higher densities, more residents are exposed and this improves the cost-effectiveness. Health gain is one of many benefits of enhancing neighbourhood walkability and future studies might consider a more comprehensive assessment of its social value (eg, social cohesion, safety and air quality).

\section{Strengths and limitations of this study}

- The well-established multistate multicohort life table approach was used to estimate the potential health benefits of investing in sidewalks to encourage physical activity.

- Health outcomes considered included reductions in mortality and morbidity, and health-adjusted life years gained.

- Findings were adjusted for self-selection effects.

- Effect estimates for the association of sidewalk availability with physical activity are potentially subject to recall bias.

- Only one intervention is considered in this study; however, to impact on walking and health, there is a need for integrated built environment interventions.

\section{INTRODUCTION}

Physical inactivity is an important risk factor for many chronic diseases, including diabetes, cardiovascular disease and some types of cancer. ${ }^{1}$ In Australia, physical inactivity ranks eighth as a risk factor for death and ninth as a risk factor for disability adjusted life years (DALYs). ${ }^{2}$ Yet despite the known benefits, too few adults in Australia ${ }^{3}$ and elsewhere ${ }^{45}$ participate in levels of physical activity optimal for health. Even small increases in physical activity reduce the risk of chronic disease and provide health benefit. ${ }^{6}$ Creating supportive built environments can cause positive shifts in population levels of physical activity and significantly reduce the burden of disease and related healthcare spending. ${ }^{7}$

There is increasing attention for the role of the built environment, and in particular neighbourhood urban form, in either facilitating or inhibiting physical activity. ${ }^{8}$ Several neighbourhood built environment characteristics, including the mix and diversity of land uses and destinations, population or residential density and street and pedestrian connectivity, are 
consistently found to be positively associated with physical activity, and in particular walking. ${ }^{9-12}$ Other built environment attributes are also important for supporting walking such as access to transit, availability and quality of sidewalks/footpaths, street appeal or aesthetics, and personal and traffic safety. ${ }^{10}{ }^{13-17}$ These built environment characteristics collectively contribute to the 'walkability' of a neighbourhood, which is found to be positively associated with walking and other physical activity behaviours. ${ }^{9}{ }^{18}$ Creating 'walkable' neighbourhoods would also produce cobenefits and meet other social objectives such as sustainable transportation, reduction in air pollution and traffic noise and increased social connectivity. ${ }^{19}{ }^{20}$ If these health and social benefits could be realised at a reasonable cost, then environmental interventions that improve the walkability of residential neighbourhoods may be a cost-effective means of promoting health and well-being.

There are few economic evaluations of environmental interventions and most of the available evidence relates to designated walking trails or transport-related infrastructure, such as cycle paths. ${ }^{21-23}$ However, none of these studies adjusted effect estimates for bias introduced by residential self-selection and only one ${ }^{23}$ controls for other built environment characteristics. Self-selection refers to the bias introduced by residents who choose to live in neighbourhoods that facilitate walking because they prefer to walk, rather than the neighbourhoods causing them to walk more. ${ }^{24}$ A systematic review found the median benefit to cost ratio to be $5: 1$, suggesting that every $\$ 1$ invested in transport-related infrastructure generates benefits worth $\$ 5$ (including the financial value of reduced demand on the healthcare system). ${ }^{25}$ Despite this important finding, the authors hesitated from drawing policy-relevant conclusions citing a lack of transparency and variation in the methods employed in studies as a cause for concern. The need to account more accurately for the effect of built environment measures on physical activity was highlighted in a recent systematic review of transport economic evaluations. ${ }^{26}$

Others have monetised the health benefits of urban form in relation to walking and health. Boarnet $e t a l^{27}$ used regression analysis on travel survey data from Portland, Oregon, to quantify the impact of built environmental features on distance walked. Walking was translated into lives saved, with each life valued in dollar terms using published estimates of the value of a statistical life ranging from US $\$ 2.5$ million to US $\$ 7.4$ million per life saved (US\$2006). Their analysis suggested that 2 lives would be saved per year for every 1000 people exposed to a more walkable environment. While this finding is promising, missing from the work was any attempt to quantify the cost of the environmental interventions that might help realise these benefits.

While recognising the need to evaluate the complementary effects of each component of a neighbourhood that collectively enhances walkability, this paper begins this important work by focusing on one aspect, namely the presence of sidewalks. Building sidewalks is something that planners could require in all new housing, and which could be retrofitted in established neighbourhoods.

This study considers the cost-effectiveness of spending to extend the length of sidewalks in a neighbourhood to increase levels of walking and improve health. The effect estimates applied in this modelling exercise were adjusted for other built environment features (implicitly holding all other features of the neighbourhood environment constant) and for residential self-selection, which allows for the evaluation of the independent and unbiased effect of increasing sidewalks. Health-adjusted life years (HALYs) were calculated to represent the impact on health of improvements in walking. HALYs are population health measures that combine impacts on morbidity and mortality in a single metric. ${ }^{28}$

\section{METHODS \\ Overview}

This economic evaluation involved four stages: (1) estimate the effect of sidewalks on walking; (2) translate the expected increase in walking into a increase in HALYs gained and healthcare costs; (3) estimate the costs of extending sidewalk length and (4) derive estimate of economic value of investing in sidewalks to increase physical activity in terms of the cost per HALY gained. A health sector perspective was used in which the costs of sidewalks (as a health-promoting intervention) were included. An intervention of 30 years duration was assumed, a lifetime time horizon was applied and costs and benefits were discounted at 3\% (baseline scenario) to 2010 values. The $3 \%$ rate was chosen following the recommendation by the US Panel on Cost-Effectiveness in Health and Medicine. ${ }^{29}$

\section{Estimate of effect of sidewalks on walking RESIDE data}

Data for this stage of the evaluation were drawn from the RESIDential Environments Study (RESIDE) in Perth, Western Australia. RESIDE is a longitudinal study examining the relationship between urban design and a number of social outcomes, including physical activity. The opportunity for the RESIDE study arose when, in 1998, the Western Australia state government introduced new planning guidelines (the Liveable Neighbourhood Guidelines) incorporating 'New Urbanist' principles. The RESIDE study followed people relocating to new houses being built in 1 of 74 new housing developments, some of which were designed according to the Liveable Neighbourhoods guidelines. Information on the RESIDE project is detailed elsewhere. ${ }^{30}$ The RESIDE data set contains information on 1813 people of whom $59 \%$ were women, $81 \%$ were married or in de facto relationships, $67 \%$ have children living at home, $22 \%$ were university educated and $53 \%$ were either overweight or obese (average BMI was 26.05). ${ }^{30}$ 
Model estimates

We took estimates of the relationship between sidewalk length and walking behaviour from the RESIDE crosssectional baseline survey in this economic evaluation. ${ }^{31}$ Data included self-reported neighbourhood-based transportation and recreational walking, socio-demographic characteristics, attitudes towards walking and variables related to residential self-selection (ie, access to services, recreation and schools, pedestrian and cycling friendly streets and housing variety). Neighbourhood-based transportation and recreational walking had been measured using the Neighbourhood Physical Activity Questionnaire, which provides reliable estimates of the proportion of people who walk and the average minutes spent walking in a usual week, within and outside the neighbourhood. $^{32}$ This degree of specificity has proved useful in linking walking for different purposes (transport, leisure) with particular neighbourhood attributes. The built environment within $1.6 \mathrm{~km}$ around participants' homes had been assessed using Geographical Information Systems and satellite imagery to derive objectively determined measures of neighbourhood walkability (ie, land use mix, residential density and street connectivity) ${ }^{33}$ and sidewalk length. A Heckman two-staged regression model had then been used to estimate the association between sidewalk length in the neighbourhood and (1) the proportion of people walking for transport or leisure in the neighbourhood, and (2) the total minutes spent walking in the neighbourhood in a usual week among those who reported any walking. McCormack et $a l^{81}$ provide a detailed description of the method and results of the Heckman modelling, but in brief, the decision about whether or not to walk was estimated using a multivariate Probit regression followed by a sample selection-bias corrected ordinary least squares regression for minutes spent walking. Estimates of the association between sidewalk length and neighbourhood walking were then adjusted for differences in walkability, attitude towards walking, neighbourhood self-selection, age, gender and education. McCormack $e t a l^{31}$ included neighbourhood preferences in the probit and linear regression models to adjust for the effect of residential self-selection on walking.

\section{Modelling health outcomes and healthcare costs}

To translate the Heckman model estimates of walking as a function of sidewalk length into an estimate of gained HALYs and healthcare costs avoided, we used the mathematical model developed for the Assessing Cost-effectiveness in Prevention (ACE-Prevention) project. ${ }^{34}$ Baseline health and cost parameters were updated from 2003 to 2010. See online supplementary material for further detail.

Gained HALYs and costs were measured over the lifetime of a 2010 Australian neighbourhood adult population. A macro simulation approach was used to calculate changes in HALYs arising from expected changes in physical activity levels due to walking following a hypothetical increase in sidewalk length. We applied a proportional multistate multicohort life table model in which five physical activity-related diseases were explicitly modelled, comparing the lifetime number of HALYs for a population that is exposed to the intervention with an identical population under status quo conditions. ${ }^{35}$ In the proportional multistate life table model, health outcomes are calculated from changes in the incidence of physical activity-related diseases (ischaemic heart disease, stroke, type 2 diabetes, colon cancer and breast cancer in women). ${ }^{1}$ Changes in the incidence of diseases lead to corresponding changes in prevalence in later years, and from there to changes in mortality and years lived with disability. Epidemiological data for the diseases were derived from the Global Burden of Disease $2010^{36}$ study with the help of DISMOD $\mathrm{II}^{37}$ to obtain parameters not explicitly reported (incidence and case death from prevalence and mortality). The conceptual model for DISMOD II is based on the multistate life table. ${ }^{38}$ HALYs are estimated as years of life lived adjusted for health-related quality of life, using Global Burden of Disease disability weights. ${ }^{39}$ For more detail, refer to the online supplementary material.

\section{Intervention costs}

The intervention was defined as spending to increase the length of sidewalks by $10 \mathrm{~km}$ in each $1.6 \mathrm{~km}$ road network buffer surrounding a participant's home and maintaining this for 30 years. The cost of installing a standard sidewalk was determined to be $\mathrm{A} \$ 172$ (2012/ 2013) per square metre based on estimates of actual sidewalk replacement costs obtained from council documents. ${ }^{40-42}$ Previous research used a value of $A \$ 70$ per linear metre for a sidewalk of $1.8 \mathrm{~m}$ in width; ${ }^{16}$ however, more recent evidence suggests that the price per square metre is likely to be higher. ${ }^{40-42}$ The initial capital cost and periodic maintenance costs were included, assuming sidewalk replacement after 15 years.

\section{Exposure}

More people than just the survey participants will benefit from the investment in sidewalks, and so we also need to take into account residential density to compute the number of people 'exposed' to the intervention. Planning guidelines for Perth from 2003 suggest an average residential density of 9 dwellings/ha in lowdensity areas. ${ }^{43}$ Assuming an average of 2.55 adults per dwelling, this yields an estimate of 19000 potential beneficiaries within a $1.6 \mathrm{~km}$ circular area. We use this figure in our baseline estimate and revisit the assumption in our sensitivity analysis and discussion.

\section{Intervention cost-effectiveness}

An incremental cost-effectiveness ratio (ICER) is evaluated for the intervention by comparing model outcomes given current levels of physical activity with those that would be expected following an increase in the length of sidewalks in each neighbourhood. The net costs of 
the intervention are the costs of installing and maintaining the sidewalks plus the net effect that changes in health have on healthcare costs in future. The reduction in diseases related to physical inactivity lowers treatment cost in the short and medium term, but it also means that new healthcare costs may be incurred by people who now go on to develop unrelated conditions in their added years of life.

Ninety-five per cent uncertainty intervals (UIs) were determined for all outcome measures by Monte Carlo simulation (2000 iterations), using the Excel add-in tool Ersatz (Epigear, V.1.01). Uncertainty distributions around input parameters are described in table 1 . The results of the Monte Carlo analysis were then used to determine the probability of intervention costeffectiveness against a cost-effectiveness threshold of A $\$ 60000$ per HALY, which is a commonly used threshold in the Australian context. ${ }^{44} 45$

In addition, we vary the cost of sidewalk construction and maintenance, the residential density in the neighbourhood where the new sidewalks are located and the discount rate in a series of one- and two-way sensitivity analyses. We also combine the cost of sidewalks with residential density to find the most cost-effective mix. All scenarios, including the baseline, are presented in table 2.

\section{RESULTS}

Incremental cost-effectiveness

In the baseline scenario, the cost of installing and maintaining an extra $10 \mathrm{~km}$ of sidewalks is $\mathrm{A} \$ 4.1$ million per neighbourhood. This investment is expected to gain 24 HALYs over the life span of the neighbourhood adult population (95\% UI 20 to 28) (table 3, Scenario 1. Baseline). After taking into account the net effect on healthcare costs, the total cost increases to $\mathrm{A} \$ 4.2$ million. The ICER is $\mathrm{A} \$ 176000$ per HALY gained $(95 \%$ UI $\mathrm{A} \$ 148000$ to A $\$ 203$ 000), which lies well above the A $\$ 60000 /$ HALY threshold (figure 1). Under the baseline scenario assumptions, there was $0 \%$ probability of this intervention being under $\mathrm{A} \$ 60000$ per HALY (table 4 and figure 2).

\section{Sensitivity results}

The results are extremely sensitive to some of the assumptions made in the analysis, especially with respect to changes in residential density, which materially affects the number of people benefiting from the intervention (table 4). High residential density, or medium density if the cost of installing sidewalks is low, both generate ICERs consistently below the A $\$ 60000$ per HALY threshold (table 4 and figure 2). For the medium-density scenario, the probability of being under this threshold was $79 \%$.

\section{DISCUSSION}

\section{Principal findings}

While sidewalks are important in supporting walking, these results show that investing in increasing the length of sidewalks in a neighbourhood, independent of other modifications to create a more walkable neighbourhood, is unlikely to be a cost-effective method of improving health at the existing (low) levels of residential density in Perth. That is to say, other means of increasing physical activity such as GP 'prescriptions' for physical activity, social marketing campaigns and supported use of pedometers were estimated to generate health benefits at lower net cost. ${ }^{34}$

The analysis is limited to the outcomes associated with the most important diseases related to physical inactivity. Other health benefits, including improved safety for pedestrians, and broader social benefits such as those related to less reliance on motor vehicles, or to any increase in sense of community that results from seeing more of one's neighbours on the street, have not been included because we lack data on the impact on these measures. ${ }^{47} 48$ Thus, one cannot conclude from this work that investing in extending sidewalks is not costeffective per se. Health gain is, to some extent, an externality or fortunate by-product of decisions that make neighbourhoods more walkable and ultimately more liveable. A more complete evaluation would reflect the value of all outcomes of importance.

The model estimates used for the association between sidewalks and walking also have limitations. ${ }^{31}$ The

Table 1 Uncertainty input parameters

\begin{tabular}{|c|c|c|c|}
\hline Parameter & Mean (SD) & Distribution & Source \\
\hline Proportion doing any walking & $62.40 \%(19.86 \%)$ & Beta & 31 \\
\hline $\begin{array}{l}\text { Extra walkers per additional } 10 \mathrm{~km} \\
\text { sidewalk (RESIDE sample) }\end{array}$ & $0.66 \%(9.68 \%)$ & Beta & 31 \\
\hline Average minutes walked per walker & $151.10(123.15)$ & Lognormal & 31 \\
\hline $\begin{array}{l}\text { Extra minutes walked per week per } \\
10 \mathrm{~km} \text { sidewalk }\end{array}$ & $5.26(2.93)$ & Lognormal & 31 \\
\hline Disease cost offset & $\begin{array}{l}\text { See supplementary } \\
\text { table S1 }\end{array}$ & Uniform & $\begin{array}{l}\text { Australian Institute of Health and Welfare } \\
\text { Impacts Study } 2001 \text {. Maximum/minimum } \\
\text { assumed at } \pm 25 \% \text { of mean value }\end{array}$ \\
\hline Relative risks of diseases & $\begin{array}{l}\text { See supplementary } \\
\text { table S2 }\end{array}$ & Normal (In RR) & Physical activity ${ }^{1}$ and Diabetes risks ${ }^{46}$ \\
\hline
\end{tabular}


Table 2 Evaluated scenarios

\begin{tabular}{|c|c|c|c|c|}
\hline Scenarios & $\begin{array}{l}\text { Cost sidewalk } \\
\text { per square } \\
\text { metre } \\
\left(\mathrm{A} \$ 2010 / \mathrm{m}^{2}\right)\end{array}$ & $\begin{array}{l}\text { Residential density: } \\
\text { dwelling per hectare } \\
\text { (number of adults*) }\end{array}$ & $\begin{array}{l}\text { Discount rate } \\
(\%) \text { costs/ } \\
\text { health }\end{array}$ & $\begin{array}{l}\text { Other healthcare } \\
\text { costs in added life } \\
\text { years excluded }\end{array}$ \\
\hline 1. Baseline & 166 & $9(19000)$ & 3 & No \\
\hline 2. Low cost sidewalk & 136 & $9(19000)$ & 3 & No \\
\hline 3. High cost sidewalk & 227 & $9(19000)$ & 3 & No \\
\hline 4. Low density & 166 & $20(41000)$ & 3 & No \\
\hline 5. Medium density & 166 & $30(62000)$ & 3 & No \\
\hline 6. High density & 166 & $60(123000)$ & 3 & No \\
\hline 7. Low density/low cost sidewalk & 136 & $20(41000)$ & 3 & No \\
\hline 8. Low density/high cost sidewalk & 227 & $20(41000)$ & 3 & No \\
\hline 9. Medium density/low cost sidewalk & 136 & $30(62000)$ & 3 & No \\
\hline 10. Medium density/high cost sidewalk & 227 & $30(62000)$ & 3 & No \\
\hline 11. High density/low cost sidewalk & 136 & $60(123000)$ & 3 & No \\
\hline 12. High density/high cost sidewalk & 227 & $60(123000)$ & 3 & No \\
\hline 13. Discount health $0 \%$ and costs $0 \%$ & 166 & $9(19000)$ & 0 & No \\
\hline 14. Discount health $1 \%$ and costs $3 \%$ & 166 & $9(19000)$ & $3 / 1$ & No \\
\hline 15. Discount health $5 \%$ and costs $5 \%$ & 166 & $9(19000)$ & 5 & No \\
\hline 16. Healthcare costs prolonged life excluded & 166 & $9(19000)$ & 3 & Yes \\
\hline
\end{tabular}

estimates of walking, while specific to the neighbourhood context, were self-reported and therefore prone to recall and memory errors. Further, not all walking trips, either for transportation or recreation, are within the neighbourhood. Our context-specific approach, which matched neighbourhood sidewalks with neighbourhood walking, is a strength of this study. However, this approach may underestimate the total influence of sidewalks on walking, as some walking that originated from within the neighbourhood may have also included some walking outside the neighbourhood. Furthermore, sidewalk provision may also support more vigorous-intensity physical activities such as jogging and running, which can provide health benefits over and above those provided by more moderate-intensity physical activity such as walking. ${ }^{49} 50$ Since this was a sample of mostly younger and middle-aged people who were about to move into new housing developments in suburban Australia, the external validity of our findings is greatest when applied in similar settings. The more the population of interest differs from out study population, the more caution should be applied in the use of our findings. However, in situations where better suited alternative data are not available, our estimates could serve as a 'best available estimate' if the alternative is no estimate at all, with the risk that the health benefits of walking associated with sidewalks are ignored in the decisionmaking process.

\section{Sidewalk within the broader context}

Investment in sidewalks might have a bigger marginal impact on physical activity and produce more health benefits if it were accompanied by complementary efforts to improve other aspects of walkability such as the number and mix of destinations that people can walk to (land use mix), street connectivity and the aesthetic quality of the physical environment. People not only need something to walk on, but also somewhere to walk to. Such a comprehensive approach is likely to have additive and synergistic benefits as each component of walkability complements the others. It might be also necessary to have other health promotion strategies in place, in addition to the built environment changes, to maximise the impact of this investment on physical activity.

Notably, our results show strongly the importance of residential density. In higher density neighbourhoods, the fixed costs of neighbourhood improvements are spread over more people, leading to greater overall benefit, which improves cost-effectiveness. By international standards, density in Australia is very low. While one of the aims of the Western Australian Liveable Neighbourhood Guidelines is to increase density, density remained low, ${ }^{43}$ there is still a demand for large houses on large blocks in Australian cities, with little appetite to mandate higher densities. Nevertheless, policies such as the Liveable Neighbourhood Guidelines are influential in changing practice, and average densities of up to 19 houses per hectare are now being observed in green-field developments in Perth. ${ }^{51}$ Although that is an improvement over 9 houses per hectare, at 19 houses per hectare, the population density is expected to be $\sim 40000$ people in a neighbourhood, which implies zero probability for the installation of sidewalks to be cost-effective from the perspective of this study (table 2).

Other studies found more favourable cost-effectiveness results for sidewalks. For example, using a sophisticated spatial analysis but what they considered a 'back-of-the-envelope' economic analysis, Guo and Gandavarapu ${ }^{23}$ found 


\begin{tabular}{|c|c|c|c|c|c|c|}
\hline Scenarios & HALYs & $\begin{array}{l}\text { Intervention } \\
\text { cost }^{\star}(A \$)\end{array}$ & $\begin{array}{l}\text { Healthcare cost } \\
\text { offsets } †(A \$)\end{array}$ & $\begin{array}{l}\text { Costs prolonged life } \\
\text { (A\$) }\end{array}$ & Net cost (A\$) & ICER (A\$/HALY) \\
\hline 1. Baseline & $24(20,28)$ & 4077694 & $\begin{array}{l}-232232(-185343 \\
-288222)\end{array}$ & $\begin{array}{l}313910(264636 \\
374670)\end{array}$ & $\begin{array}{l}4159373 \text { (4 } 134899, \\
4186344)\end{array}$ & $\begin{array}{l}175782(147983, \\
203463)\end{array}$ \\
\hline 2. Low cost sidewalk & $24(20,28)$ & 3340761 & $\begin{array}{l}-232232(-185343 \\
-288222)\end{array}$ & $\begin{array}{l}313910(264636 \\
374670)\end{array}$ & $\begin{array}{l}3422440 \text { (3 } 397967, \\
3449411)\end{array}$ & $\begin{array}{l}144635 \text { (121 911, } \\
167330)\end{array}$ \\
\hline 3. High cost sidewalk & $24(20,28)$ & 5576124 & $\begin{array}{l}-232232(-185343 \\
-288222)\end{array}$ & $\begin{array}{l}313910(264636 \\
374670)\end{array}$ & $\begin{array}{l}5657802(5633329, \\
5684774)\end{array}$ & $\begin{array}{l}239115(201101, \\
276963)\end{array}$ \\
\hline 4. Low density & $51(44,61)$ & 4077694 & $\begin{array}{l}-501132(-399951 \\
-621953)\end{array}$ & $\begin{array}{l}677386(571056, \\
808499)\end{array}$ & $\begin{array}{l}4253948 \text { (4 } 201137, \\
4312 \text { 149) }\end{array}$ & $\begin{array}{l}83303(70416, \\
96162)\end{array}$ \\
\hline 5. Medium density & $78(67,92)$ & 4077694 & $\begin{array}{l}-757809(-604803 \\
-940514)\end{array}$ & $\begin{array}{l}1024339(863548, \\
1222608)\end{array}$ & $\begin{array}{l}4344224(4264364, \\
4432236)\end{array}$ & $\begin{array}{l}56251(47635 \\
64908)\end{array}$ \\
\hline 6. High density & $154(132$ 182) & 4077694 & $\begin{array}{l}-1503396(-1199852 \\
-1865858)\end{array}$ & $\begin{array}{l}2032157(1713168, \\
2425497)\end{array}$ & $\begin{array}{l}4606455 \text { (4 } 448024, \\
4781059)\end{array}$ & $\begin{array}{l}30057(25527, \\
34652)\end{array}$ \\
\hline 7. Low density/low cost sidewalk & $51(44,61)$ & 3340761 & $\begin{array}{l}-501132(-399951 \\
-621953)\end{array}$ & $\begin{array}{l}677386(571056, \\
808499)\end{array}$ & $\begin{array}{l}3517015 \text { (3 } 464205, \\
3575216)\end{array}$ & $\begin{array}{l}68869(58276 \\
79413)\end{array}$ \\
\hline 8. Low density/high cost sidewalk & $51(44,61)$ & 5576124 & $\begin{array}{l}-501132(-399951 \\
-621953)\end{array}$ & $\begin{array}{l}677386(571056 \\
808499)\end{array}$ & $\begin{array}{l}5752378(5699567, \\
5810579)\end{array}$ & $\begin{array}{l}112652(95054 \\
130236)\end{array}$ \\
\hline 9. Medium density/low cost sidewalk & $78(67,92)$ & 3340761 & $\begin{array}{l}-757809(-604803 \\
-940514)\end{array}$ & $\begin{array}{l}1024339 \text { (863 548, } \\
1222608)\end{array}$ & $\begin{array}{l}3607291 \text { (3 } 527432, \\
3695 \text { 303) }\end{array}$ & $\begin{array}{l}46706(39604 \\
53933)\end{array}$ \\
\hline 10. Medium density/high cost sidewalk & $78(67,92)$ & 5576124 & $\begin{array}{l}-757809(-604803 \\
-940514)\end{array}$ & $\begin{array}{l}1024339(863548, \\
1222608)\end{array}$ & $\begin{array}{l}5842654(5762794, \\
5930665)\end{array}$ & $\begin{array}{l}75659(63987, \\
87309)\end{array}$ \\
\hline 11. High density/low cost sidewalk & $154(132$ 182) & 3340761 & $\begin{array}{l}-1503396(-1199852 \\
-1865858)\end{array}$ & $\begin{array}{l}2032157(1713168, \\
2425497)\end{array}$ & $\begin{array}{l}3869523 \text { (3 } 711091, \\
4044 \text { 126) }\end{array}$ & $\begin{array}{l}25246(21468 \\
29078)\end{array}$ \\
\hline 12. High density/high cost sidewalk & $154(132$ 182) & 5576124 & $\begin{array}{l}-1503396(-1199852 \\
-1865858)\end{array}$ & $\begin{array}{l}2032157(1713168 \\
2425497)\end{array}$ & $\begin{array}{l}6104885(5946453, \\
6279489)\end{array}$ & $\begin{array}{l}39840 \text { (33 798, } \\
45955)\end{array}$ \\
\hline 13. Discount health $0 \%$ and costs $0 \%$ & $57(49,67)$ & 4980000 & $\begin{array}{l}-451438(-360947 \\
-559008)\end{array}$ & $\begin{array}{l}815905 \text { (691 928, } \\
969496)\end{array}$ & $\begin{array}{l}5344467 \text { (5 } 279735, \\
5422494)\end{array}$ & $\begin{array}{l}94735(80509 \\
108668)\end{array}$ \\
\hline 14. Discount health $1 \%$ and costs $3 \%$ & 42 (36 to 49$)$ & 4077694 & $\begin{array}{l}-231952(-186346 \\
-284915)\end{array}$ & $\begin{array}{l}580915(495475, \\
683747)\end{array}$ & $\begin{array}{l}4426658 \text { (4 } 373856, \\
4489457)\end{array}$ & $\begin{array}{l}106881 \text { (92 107, } \\
122 \text { 033) }\end{array}$ \\
\hline 15. Discount health $5 \%$ and costs $5 \%$ & $15(12,17)$ & 3666193 & $\begin{array}{l}-159890(-127587 \\
-198580)\end{array}$ & $\begin{array}{l}182938(153130 \\
219227)\end{array}$ & $\begin{array}{l}3689241 \text { (3 } 673755, \\
3706601)\end{array}$ & $\begin{array}{l}254664 \text { (213 699, } \\
295717)\end{array}$ \\
\hline $\begin{array}{l}\text { 16. Healthcare costs prolonged life } \\
\text { excluded }\end{array}$ & $24(20,28)$ & 4077694 & $\begin{array}{l}-232232(-185343 \\
-288222)\end{array}$ & $\begin{array}{l}313910(264636 \\
374670)\end{array}$ & $\begin{array}{l}3845462 \text { (3 } 789472, \\
3892351)\end{array}$ & $\begin{array}{l}162609(134756, \\
190513)\end{array}$ \\
\hline
\end{tabular}




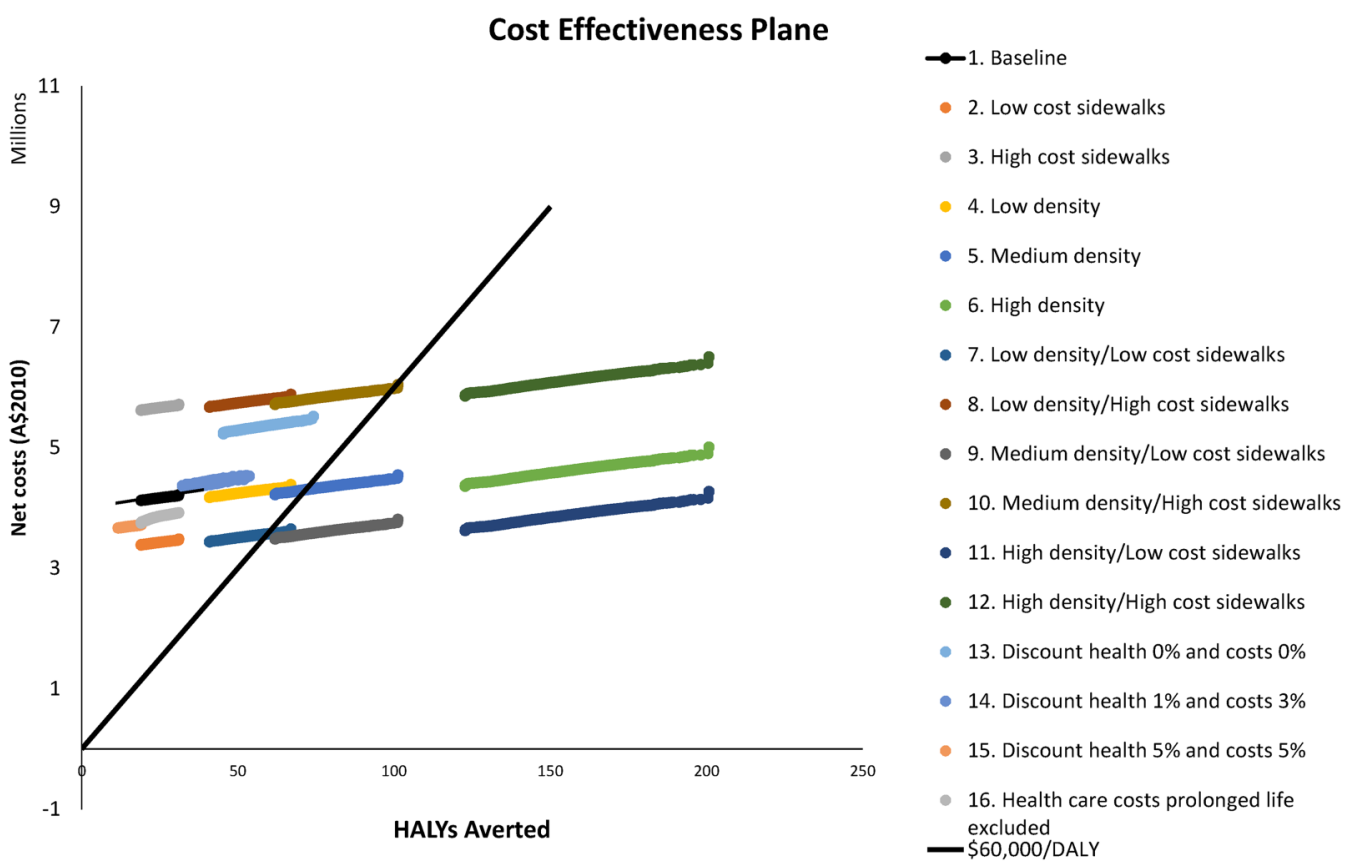

Figure 1 Cost-effectiveness plane for investing in sidewalks in a neighbourhood, baseline and alternative scenarios compared with the status quo.

Table 4 Probability of being under $\mathrm{A} \$ 60000$ per health-adjusted life year threshold

\begin{tabular}{lc}
\hline Scenario & Probability (\%) \\
\hline Baseline & 0 \\
Low cost sidewalk & 0 \\
High cost sidewalk & 0 \\
Low density & 0 \\
Medium density & 79 \\
High density & 100 \\
Low density/low cost sidewalk & 5 \\
Low density/high cost sidewalk & 0 \\
Medium density/low cost sidewalk & 100 \\
Medium density/high cost sidewalk & 0 \\
High density/low cost sidewalk & 100 \\
High density/high cost sidewalk & 100 \\
Discount health 0\% and costs 0\% & 0 \\
Discount health 1\% and costs 3\% & 0 \\
Discount health 5\% and costs 5\% & 0 \\
Healthcare costs prolonged life excluded & 0 \\
\hline
\end{tabular}

that increased sidewalk prevalence in Dane County, Wisconsin, USA, would deliver a cost-benefit ratio of 1.87 . The contrast with our findings could be due to a range of factors, including the inability in that study to adjust for residential self-selection, the assumption that additional energy spent on active transport directly translate to lower obesity rates (without dietary compensation) where we modelled the impact via physical activity and differences in the built environment such as housing density.

\section{Policy implications}

Retro-fitting established neighbourhoods to improve walkability is challenging as it involves changing existing infrastructure and housing stock. Such change is often resisted by residential and government bodies and communities. Infrastructure improvements likely to improve health will require a comprehensive long-term strategy involving integrated planning of infrastructure, housing, transport, land use and urban design. ${ }^{52}$ To this end, the development industry has an important role to play in providing leadership in developing new models for homes in green-field sites that meet the need for more compact developments for a healthier and more sustainable future. Similarly, planning regulations relating to shared occupancy, infill development and housing renewal should aim to increase higher density housing supply, resulting in greater use of existing infrastructure such as sidewalks, transportation, public open space and utilities.

The challenges of retro-fitting existing neighbourhoods and our findings here on the significance of walking draw attention to the need to design pedestrianfriendly neighbourhoods from the outset to facilitate active transport and recreational walking.

\section{CONCLUSION}

This work adds to a growing evidence base examining the cost-effectiveness of intervening in the built environment as a means of increasing physical activity and improving health and social outcomes. It points to the potential offered by neighbourhood redevelopment yet highlights the need for a comprehensive strategy that seeks both to improve all elements of walkability including land use mix and street connectivity. In particular, it highlights the importance of residential density as a 


\section{Cost Effectiveness Acceptability Curve}

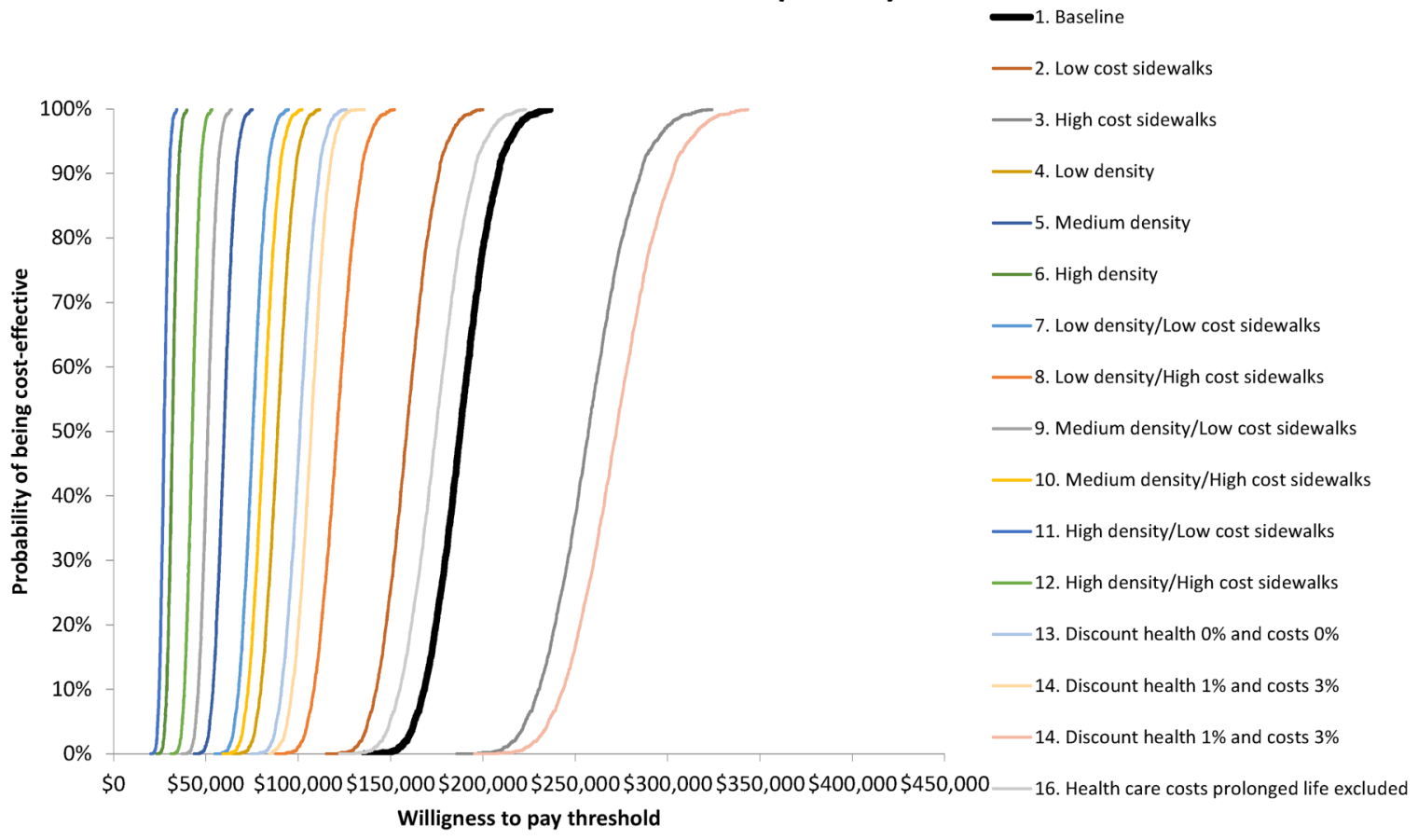

Figure 2 Cost-effectiveness acceptability curve for investing in sidewalks in a neighbourhood, baseline and alternative scenarios compared with the status quo.

mechanism through which the cost-effectiveness of infrastructure is affected because the higher the density, the lower the fixed cost per person who has access to that infrastructure.

\section{Author affiliations}

${ }^{1}$ The University of Queensland, School of Public Health, Herston, Queensland, Australia

${ }^{2}$ McCaughey Centre, Melbourne School of Population and Global Health, The University of Melbourne, Parkville, Victoria, Australia

${ }^{3}$ Centre for Excellence in Intervention Prevention Science, Carlton South, Victoria, Australia

${ }^{4}$ Department of Community Health Sciences, Cumming School of Medicine, University of Calgary, Calgary, Alberta, Canada

${ }^{5}$ Nuffield Department of Population Health, The British Heart Foundation Centre on Population Approaches for Non-Communicable Disease Prevention, University of Oxford, Oxford, UK

${ }^{6}$ Department of Public Health, The Australian Prevention Partnership Centre, La Trobe University, Melbourne, Victoria, Australia

Acknowledgements JLV, BZ-D, LG, BG-C and AS are part of the NHMRC CRE in Healthy, Liveable Communities (APP1061404). JLV and AMMH are supported by funding from the NHMRC Centre for Research Excellence (CRE) in Obesity Policy and Food Systems (APP1041020). BZ-D is supported by an Australian Postgraduate Award. AS acknowledges the financial support provided to him to carry out this work by the Alberta Heritage Foundation for Medical Research, the Canadian Institutes of Health Research and the Public Health Agency of Canada. He also acknowledges the contribution made by Pierre Guenette to the estimation of intervention costs. GRM is supported by a Canadian Institutes of Health Research New Investigator Award.

Contributors AS, BG-C, JLV and GRM developed the initial design of the study, oversaw and supervised the empirical work and contributed in drafting the first manuscript. LG and BZ-D revised and amended the first manuscript and all authors revised the final version of the paper. LJC set up the original economic model and BZ-D revised and updated the economic model with demographic, cost and epidemiological data, ran the models and wrote the results. BZ-D drafted the abstract and appendix and JLV revised them. LG GRM and AS provided the interventions costs. AMMH produced the epidemiological estimates. All authors contributed to and commented on the final version of the manuscript.

Funding This research received no specific grant from any funding agency in the public, commercial or not-for-profit sectors.

Competing interests None declared.

Provenance and peer review Not commissioned; externally peer reviewed.

Data sharing statement The model to estimate health outcomes and healthcare costs is available on request from the first author of this study.

Open Access This is an Open Access article distributed in accordance with the Creative Commons Attribution Non Commercial (CC BY-NC 4.0) license, which permits others to distribute, remix, adapt, build upon this work noncommercially, and license their derivative works on different terms, provided the original work is properly cited and the use is non-commercial. See: http:// creativecommons.org/licenses/by-nc/4.0/

\section{REFERENCES}

1. Bull FC, Armstrong TP, Dixon T, et al. Physical inactivity. In: Ezzati M, Lopez A, Rodgers A, et al., eds. Comparative quantification of health risks: global and regional burden of disease due to selected major risk factors. Vol 1. Geneva, Switzerland: WHO, 2004:729-881.

2. Institute for Health Metrics and Evaluation (IHME). GBD compare. Seattle, WA: IHME, University of Washington, 2015 (10 November 2015). http://www.healthdata.org/data-visualization/gbd-compare

3. Australian Bureau of Statistics. Australian Health Survey: Physical Activity, 2011-12 2015 (22 September 2015). http://www.abs.gov.au/ ausstats/abs@.nsf/Lookup/ D4495467B7F7EB01CA257BAC0015F593?opendocument

4. Center for Disease Control and Prevention. State Indicator Report on Physical Activity 2014. Atlanta, GA: US Department of Health and Human Services, 2014 (1 September 2015). http://www.cdc.gov/ physicalactivity/downloads/pa_state_indicator_report_2014.pdf

5. Statistics Canada. Directly measured physical activity of Canadian adults 2007 to 2011. Ottawa, Ontario, Canada, 2013 (28 October 2015). http://www.statcan.gc.ca/pub/82-625-x/2013001/article/ 11807-eng.htm 
6. Lee IM, Shiroma EJ, Lobelo F, et al. Effect of physical inactivity on major non-communicable diseases worldwide: an analysis of burden of disease and life expectancy. Lancet 2012;380:219-29.

7. Sallis JF, Spoon C, Cavill N, et al. Co-benefits of designing communities for active living: an exploration of literature. Int J Behav Nutr Phys Act 2015;12:30.

8. Barnes R, Giles-Corti B, Bauman A, et al. Does neighbourhood walkability moderate the effects of mass media communication strategies to promote regular physical activity? Ann Behav Med 2013;45(Suppl 1):S86-94.

9. Christian HE, Bull FC, Middleton NJ, et al. How important is the land use mix measure in understanding walking behaviour? Results from the RESIDE study. Int J Behav Nutr Phys Act 2011;8:55.

10. Knuiman MW, Christian HE, Divitini ML, et al. A longitudinal analysis of the influence of the neighborhood built environment on walking for transportation: the RESIDE study. Am J Epidemiol 2014;180:453-61.

11. Wilson AM, Cope A. Value for money of walking and cycling interventions: making the case for investment in active travel. UK: Sustrans Research and Monitoring Unit, 2011.

12. Van Holle V, Deforche B, Van Cauwenberg J, et al. Relationship between the physical environment and different domains of physical activity in European adults: a systematic review. BMC Public Health 2012;12:807

13. Astell-Burt T, Feng $X$, Kolt GS. Identification of the impact of crime on physical activity depends upon neighbourhood scale: multileve evidence from 203,883 Australians. Health Place 2015;31:120-3.

14. Koohsari MJ, Kaczynski AT, Giles-Corti B, et al. Effects of access to public open spaces on walking: is proximity enough? Landsc Urban Plann 2013;117:92-9.

15. Cerin E, Cain KL, Conway TL, et al. Neighborhood environments and objectively measured physical activity in 11 countries. Med Sci Sports Exerc 2014;46:2253-64.

16. Gunn LD, Lee Y, Geelhoed E, et al. The cost-effectiveness of installing sidewalks to increase levels of transport-walking and health. Prev Med 2014;67:322-9.

17. De Bourdeaudhuij I, Sallis JF, Saelens BE. Environmental correlates of physical activity in a sample of Belgian adults. Am J Health Promot 2003;18:83-92

18. Learnihan V, Van Niel KP, Giles-Corti B, et al. Effect of scale on the links between walking and urban design. Geogr Res 2011;49:183-91.

19. Rissel CE. Active travel: a climate change mitigation strategy with co-benefits for health. N S W Public Health Bull 2009;20:10-13.

20. Giles-Corti B, Foster S, Shilton T, et al. The co-benefits for health of investing in active transportation. N S W Public Health Bull 2010;21:122-7.

21. Wang G, Macera CA, Scudder-Soucie B, et al. A cost-benefit analysis of physical activity using bike/pedestrian trails. Health Promot Pract 2005;6:174-9.

22. Stokes RJ, MacDonald J, Ridgeway G. Estimating the effects of light rail transit on healthcare costs. Health Place 2008;14:45-58.

23. Guo JY, Gandavarapu S. An economic evaluation of health-promotive built environment changes. Prev Med 2010;50 (Suppl 1):S44-S9.

24. Cao X, Mokhtarian PL, Handy SL. Examining the impacts of residential self-selection on travel behaviour: a focus on empirical findings. Transport Rev 2009;29:359-95.

25. Cavill N, Kahlmeier S, Rutter $\mathrm{H}$, et al. Corrigendum to 'Economic analyses of transport infrastructure and policies including health effects related to cycling and walking: a systematic review' [Transport Policy 15(5) (2008) 291-304]. Transport Policy 2009;16:46.

26. Brown V, Zapata-Diomedi B, Moodie M, et al. A systematic review of economic analyses of active transport interventions that include physical activity benefits. Transport Policy 2016;45:190-208.

27. Boarnet MG, Greenwald M, McMillan TE. Walking, urban design, and health: toward a cost-benefit analysis framework. J Plan Educ Res 2008;27:341-58.

28. Gold MR, Stevenson D, Fryback DG. HALYs and QALYs and DALYs, oh my: similarities and differences in summary measures of population health. Annu Rev Public Health 2002;23:115-34.

29. Gold MR. Cost-effectiveness in health and medicine. New York: Oxford University Press, 1996.

30. Giles-Corti B, Knuiman M, Timperio A, et al. Evaluation of the implementation of a state government community design policy aimed at increasing local walking: design issues and baseline results from RESIDE, Perth Western Australia. Prev Med 2008;46:46-54.

31. McCormack GR, Shiell A, Giles-Corti B, et al. The association between sidewalk length and walking for different purposes in established neighborhoods. Int J Behav Nutr Phys Act 2012;9:92.

32. Giles-Corti B, Timperio A, Cutt $\mathrm{H}$, et al. Development of a reliable measure of walking within and outside the local neighborhood: RESIDE's Neighborhood Physical Activity Questionnaire. Prev Med 2006;42:455-9.

33. Frank LD, Andresen MA, Schmid TL. Research article: Obesity relationships with community design, physical activity, and time spent in cars. Am J Prev Med 2004;27:87-96.

34. Cobiac LJ, Vos T, Barendregt JJ. Cost-effectiveness of interventions to promote physical activity: a modelling study. PLoS Med 2009;6: e1000110.

35. Barendregt J, Van Oortmarssen G, Van Hout B, et al. Coping with multiple morbidity in a life table. Math Popul Stud 1998;7:29-49.

36. Institute for Health Metrics and Evaluation. GBD Database. Seattle, WA: IHME, University of Washington, 2014.

37. Barendregt JJ. EpiGear International 2012 (cited 1 March 2015). http://www.epigear.com/index files/prevent.htm

38. Barendregt JJ, Van Oortmarssen GJ, Murray CJ, et al. A generic model for the assessment of disease epidemiology: the computational basis of DisMod II. Popul Health Metr 2003;1:4.

39. Salomon JA, Vos T, Hogan DR, et al. Common values in assessing health outcomes from disease and injury: disability weights measurement study for the Global Burden of Disease Study 2010. Lancet 2012;380:2129-43.

40. WalksVictoria. Footpaths 2014 (4 November 2014). http://www victoriawalks.org.au/Footpaths/

41. Council AC. Policy and procedures for footpath repairs and maintenance 1997 (4 November 2014). http://www.ashfield.nsw.gov. au/files/footpath_repair_and_maintenance_policy.pdf

42. Liverpool City Council. Restoration and road opening permit fees and charges 2012/13 2013 (4 November 2014). http://www.liverpool.nsw. gov.au/_data/assets/pdf_file/0018/4626/RESTO-FEES-2012-2013. pdf

43. Falconer R, Newman P, Giles-Corti B. Is practice aligned with the principles? Implementing New Urbanism in Perth, Western Australia. Transport Policy 2010;17:287-94.

44. George B, Harris A, Mitchell A. Cost-effectiveness analysis and the consistency of decision making: evidence from pharmaceutical reimbursement in Australia (1991 to 1996). Pharmacoeconomics 2001;19:1103-9.

45. Carter R, Vos T, Moodie M, et al. Priority setting in health: origins, description and application of The Australian Assessing Cost-Effectiveness initiative. Expert Rev Pharmacoecon Outcomes Res 2008;8:593-617.

46. Woodward M, Zhang X, Barzi F, et al., Asia Pacific Cohort Studies Collaboration. The effects of diabetes on the risks of major cardiovascular diseases and death in the Asia-Pacific region. Diabetes Care 2003;26:360-6.

47. Wilkerson A, Carlson NE, Yen IH, et al. Neighborhood physical features and relationships with neighbors: does positive physical environment increase neighborliness? Environ Behav 2012;44:595-615.

48. Wood L, Frank LD, Giles-Corti B. Sense of community and its relationship with walking and neighborhood design. Soc Sci Med 2010;70:1381-90.

49. Suminski RR, Heinrich KM, Poston WSC, et al. Characteristics of urban sidewalks/streets and objectively measured physical activity. J Urban Health 2008;85:178-90.

50. Suminski RR, Wasserman JA, Mayfield CA, et al. Relations between perceptions of environmental features and physical activity. Percept Mot Skills 2013;117:1091-106.

51. Hooper P, Giles-Corti B, Knuiman M. Evaluating the implementation and active living impacts of a state government planning policy designed to create walkable neighborhoods in Perth, Western Australia. Am J Health Promot 2014;28:S5-18.

52. Badland $\mathrm{H}$, Whitzman $\mathrm{C}$, Lowe $\mathrm{M}$, et al. Urban liveability: emerging lessons from Australia for exploring the potential for indicators to measure the social determinants of health. Soc Sci Med 2014;111:64-73. 